\title{
INVESTIGATING MANGROVE FRAGMENTATION CHANGES USING LANDSCAPE METRICS
}

\author{
M. Baharlouii ${ }^{1, *}$, D. Mafi Gholami ${ }^{1}$, M. Abbasi ${ }^{1}$ \\ ${ }^{1}$ Dept. of forest sciences, Faculty of natural resources and earth science, Shahrekord University, Shahrekord, Iran \\ masoomebaharloie70@gmail.com, mozhgan.abasi@gmail.com, Davoody3817@yahoo.com
}

KEY WORDS: Mangrove, Fragmentation, Persian Gulf, Khamir habitate

\begin{abstract}
:
Generally, investigation of long-term mangroves fragmentation changes can be used as an important tool in assessing sensitivity and vulnerability of these ecosystems to the multiple environmental hazards. Therefore, the aim of this study was to reveal the trend of mangroves fragmentation changes in Khamir habitat using satellite imagery and Fragstats software during a 30-year period (19862016). To this end, Landsat images of 1986, 1998, and 2016 were used and after computing the normalized difference vegetation index (NDVI) to distinguish mangroves from surrounding water and land areas, images were further processed and classified into two types of land cover (i.e., mangrove and non-mangrove areas) using the maximum likelihood classification method. By determining the extent of mangroves in the Khamir habitat in the years of 1986, 1998 and 2017, the trend of fragmentation changes was quantified using CA, NP, PD and LPI landscape metrics. The results showed that the extent of mangroves in Khamir habitat (CA) decreased in the period post-1998 (1998-2016). The results also showed that, the NP and PD increased in the period of post1998 and in contrast, the LPI decrease in this period. These results revealed the high degree of vulnerability of mangroves in Khamir habitat to the drought occurrence and are thus threatened by climate change. We hope that the results of this study stimulate further climate change adaptation planning efforts and help decision-makers prioritize and implement conservative measures in the mangrove ecosystems on the northern coasts of the PG and the GO and elsewhere.
\end{abstract}

\section{INTRODUCTION}

Among the natural sub-systems located along the world's shorelines, mangrove forests straddle both marine and terrestrial ecosystems and provide a diverse range of goods and services such as the provision of wood and marine products, prevention of damage caused by storms, provision of flood control, protection of coastlines, and control of coastal erosion, waste assimilation, recreation, and transportation required by coastal communities (Tamin et al., 2011). For thousands of years, these forests have played a major role in the economies of human societies, sustaining people's livelihoods (Kaplowitz, 2001). In the middle east, mangroves on the coast of the Persian Gulf and the Oman Sea are one of the most important remaining mangrove habitats in this region and cover an area of approximately $192 \mathrm{~km}^{2}$ along the coasts of Iran (Danehkar, 2001). Despite the importance of these ecosystem services for meeting human needs, degradation and loss of these unique coastal habitats around the world have been intensified over the past three decades, so that more than $50 \%$ of the world's mangrove forests have already been destroyed and the trend is still continuing (Alongi, 2002). Loss of a wide range of goods and services provided by this ecosystem as well as enhanced risk to mangrove-dependent human communities are the direct results of the destruction and loss of mangrove ecosystems (Kristensen et al., 2008) and (Walters et al., 2008). Therefore, investigation of long-term mangroves fragmentation changes can be used as an important tool in assessing sensitivity and vulnerability of these ecosystems to the multiple environmental hazards (Reddy et al., 2013).

\section{METHOD}

Our study area consists of mangrove forests located in the Hormozgan province on the northern coasts of the Persian Gulf and the Oman Sea. The size of the area is 10700 ha and is located in the jurisdiction of seven towns (i.e., Jask, Sirik, Minab, Bandar Abbas, Khamir, Qeshm and Bandar Lengeh). The mangrove forests of Khamir habitat have the largest extent of these communities that are composed of Harra (Avicennia marina), that occupy the largest area of these forests in Iran (Danehkar, 1998).

The Landsat images of the years 1986, 1998 and 2016 were used to analyse the fragmentation of mangrove forests over a 30 -year period (figure 1). It should be noted that the limited availability of satellite images with higher resolution obliged us to choose Landsat images for this work. Landsat images were used because of the limited availability of satellite images with higher resolution. Since cloud cover reduces the image quality and causes errors in detecting the phenomena of interest in the images, we used only images from the Landsat satellite archive that were free of cloud cover. Further, only images from the month of September when the sea level was at low tide were analysed to prevent potential bias due to phenological differences arising from the change of seasons. Although Landsat- 8 images are generally characterized by good geometric precision, to ensure maximum possible accuracy, a total of 240 ground control points with good spatial distribution throughout the study area were recorded using GPS units and Landsat- 8 images of 2016 were then georeferenced. Finally, the corrected Landsat- 8 images were then used for geometric correction of the Landsat TM images taken in 1986 and 1998. After computing the normalized difference vegetation index (NDVI) to

\footnotetext{
* Corresponding author
} 
distinguish mangroves from surrounding water and land areas (Seto and Fragkias, 2007) and (Vo et al., 2013), images were further processed and classified into two types of land cover (i.e., mangrove and non-mangrove areas) using the maximum likelihood classification method. By determining the extent of mangroves in the Khamir habitat in the years of 1986, 1998 and 2017, the trend of fragmentation was quantified using CA (total class area), NP (number of patches), PD (patch density) and LPI (largest patch index) landscape metrics in Fragments 4.2 software (figure 2).

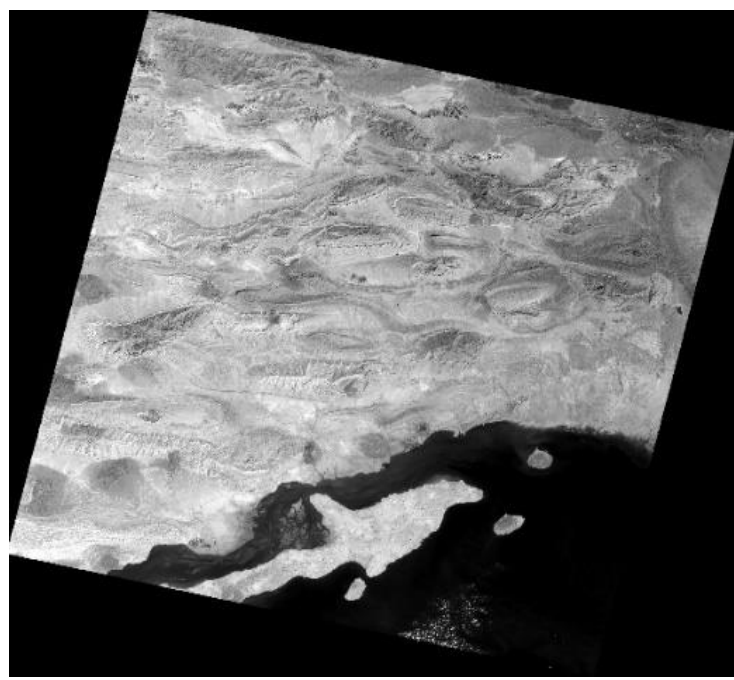

Figure 1. Landsat-8 image of Khamir habitat

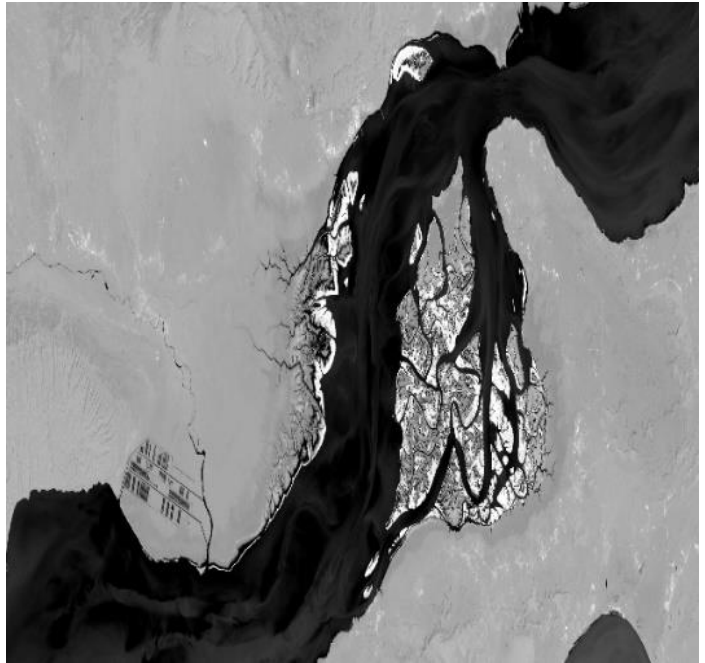

Figure 2. NDVI of mangrove in the Khamir habitat

\section{RESULTS}

Overall accuracy of all classified images consistently exceeded $90 \%$, which indicates a high level of accuracy in the classification and mapping of mangroves. The maps of mangroves showed that the area of habitat was increased in the period pre-1998 (1986-1998 (Figure 3) and was decreased between the post-1998 (1998-2016) to the pre-1998 periods (Figure 4).

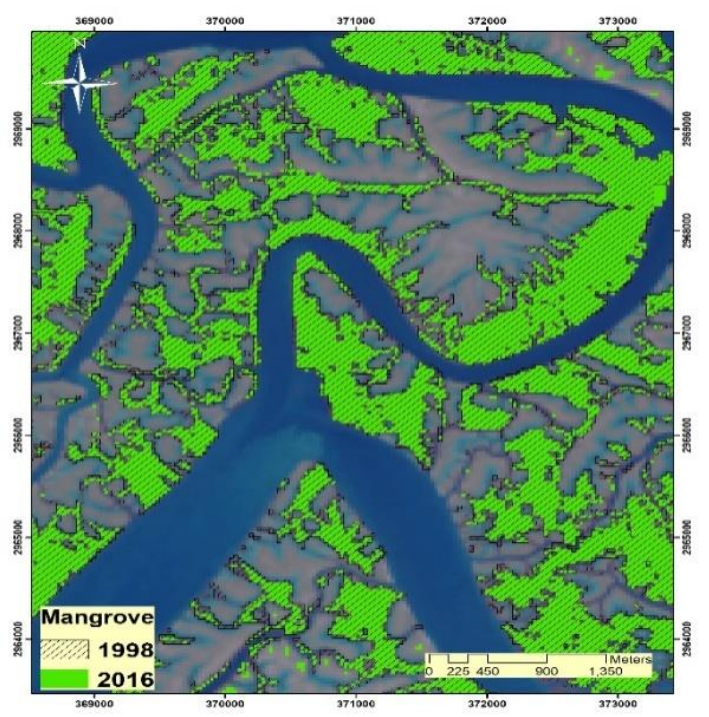

Figure 3. Extent change of Khamir habitat in the period post1998

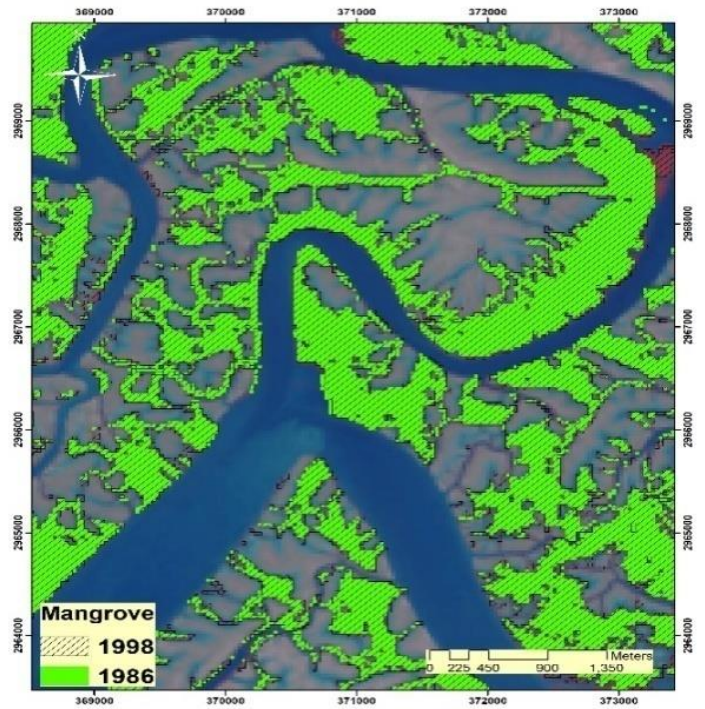

Figure 4. Extent change of Khamir habitat in the periodpre1998

Analysis of the fragmentation changes in Khamir habitat showed that the trend of CA changes was increasing and decreasing in the periods of pre- and post- 1998, respectively. Based on this, the changes of Khamir habitat area in the two periods pre- and post- 1998was 753.57 and -647.77 ha, respectively (Figure 5). The analysis of the results on NP showed that value of this index was higher in the period post1998 than post-1998 (1236 to 930). Therefore, the total number of patches was increased over the period (increasing 306 patches) (figure 6). 


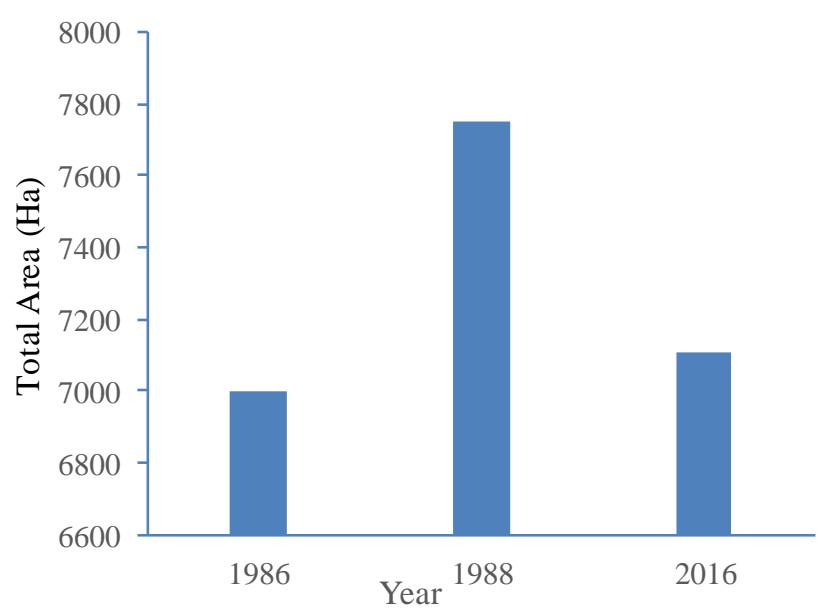

Figure 5. Total area (CA) changes in 1986, 1998 and 2016

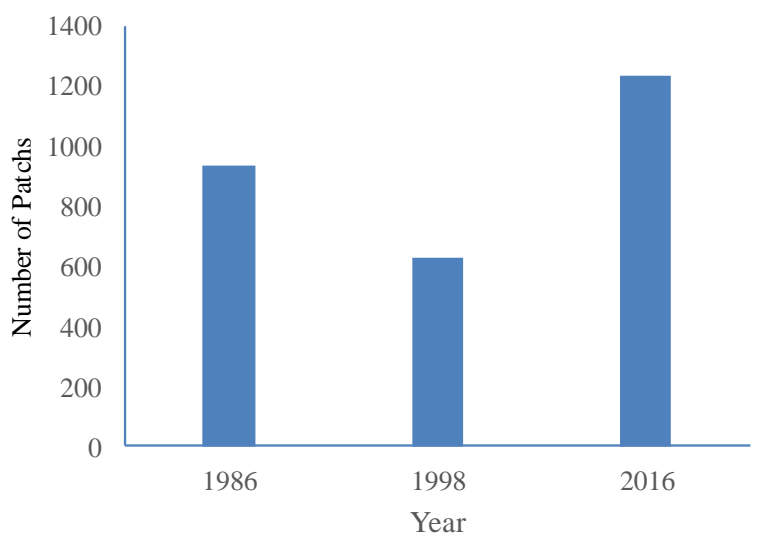

Figure 6. Changes in the Number of Patch (NP) in 1986, 1998 and 2016

The results of PD changes in Khamir habitat showed that in the period of pre-1998, the PD value was decreased from 3.13 to 1.8 and was increased from 1.8 to 17.4 in the period of post1998. Generally, the PD value of the habitat was increased over the 30-year period (figure 7). Investigating changes of LPI values showed that the value of this index was decreased in both periods of pre- and post-1998 (5.8 to 6.3 in pre-1998 and 6.3 to 5 in post-1998) (figure 8 ).

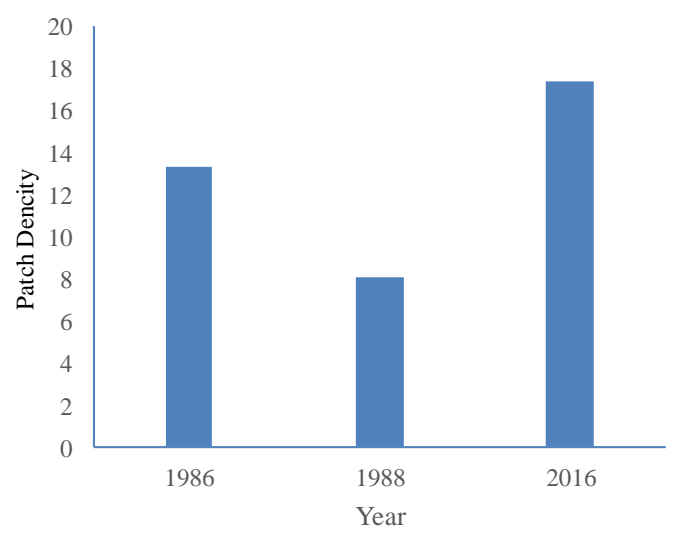

Figure 7. Changes in Patch Density (PD) in 1986, 1998 and 2016

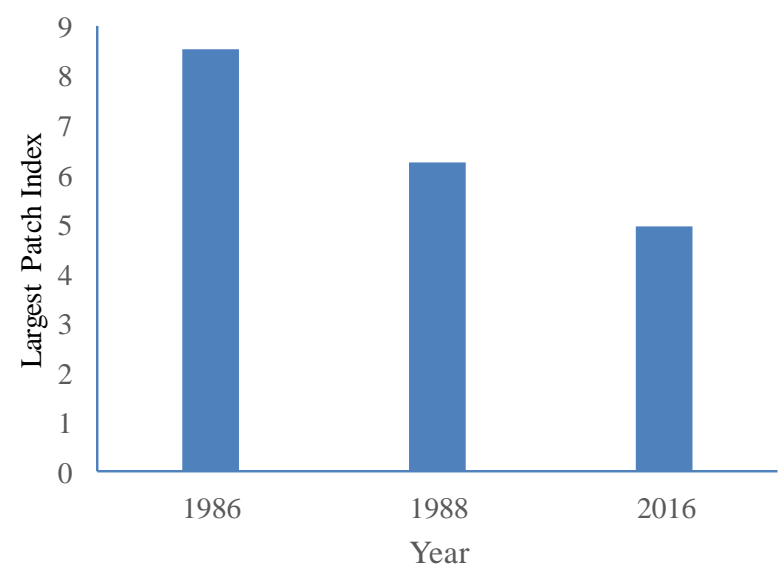

Figure 8. Changes in the Largest Patch Index (LPI) in 1986, 1998 and 2016

\section{CONCLUSIONS}

Tracking the changes of PD, NP and CA values in the Khamir habitat over the 30-yearperiod showed that during the period of pre-1998, while decreasing the NP value in the habitat, the CA value was increased in this period. The increase of $C A$ value in pre-1998 was accompanied by a reduction in the LPI value in this period. These structural changes in Khamir habitat over the period pre-1998 indicate the increase of the extent and integrity of patches in this period. However, during the period post-1998, with the decrease the habitat area, the NP and PD values were increased and the LPI was reduced due to fragmentation process. According to the principles of landscape ecology, the increase of the number and density of patches along with the decrease of the area over time indicates the degradation of ecosystem (Riitters et al., 2002), which indicate the degradation of Khamir habitat in the period of post-1998. We hope that the results of this study stimulate further climate change adaptation planning efforts and help decision-makers prioritize and implement conservative measures in the mangrove ecosystems on the northern coasts of the PG and the GO and elsewhere.

\section{REFERENCES}

Alongi, D.M., 2002. Present state and future of the world's mangrove forests. Environmental Conservation, 29, 331-349.

Danehkar, A., 1998. Marine Sensitive Areas of Iran. The Environment Scientific Quarterly Journal, 24, 28-38.

Danehkar, A., 2001. Mangroves forests zonation in Gaz and Harra international wetlands. The Environment Scientific Quarterly Journal, 34, 43-49. (In Persian).

Kaplowitz, M.D., 2001. Assessing mangrove products and services at the local level: the use of focus groups and individual interviews. Landscape and urban planning, 56(1), 53-60.

Kristensen, E., Bouillon, S., Dittmar, T., Marchand, C., 2008. Organic carbon dynamics in mangrove ecosystems: a review. Aquatic Botany, 89(2), 201-219. 
Reddy, C.S., Jha, C.S., Dadhwal, V.K., 2013. Assessment and monitoring of long-term forest cover changes in Odisha, India using remote sensing and GIS. Environmental monitoring and assessment, 185(5), 4399-4415.

Riitters, K.H., Wickham, J.D., O'neill, R.V., Jones, K.B., Smith, E.R., Coulston, J.W., Smith, J.H., 2002. Fragmentation of continental United States forests. Ecosystems, 5(8), 0815-0822.

Seto, K.C., Fragkias, M., 2007. Mangrove conversion and aquaculture development in Vietnam: A remote sensing-based approach for evaluating the Ramsar Convention on Wetlands. Global Environmental Change, 17(3), 486-500.

Tamin, N.M., Zakaria, R., Hashim, R., Yin, Y., 2011. Establishment of Avicennia marina mangroves on accreting coastline at Sungai Haji Dorani, Selangor, Malaysia. Estuarine, Coastal and Shelf Science, 94(4), 334-342.

Vo, Q.T., Oppelt, N., Leinenkugel, P., Kuenzer, C., 2013. Remote sensing in mapping mangrove ecosystems - An ObjectBased Approach. Remote Sensing, 5(1), 83-201.

Walters, B.B., Ronnback, P., Kovacs, J.M., Crona, B., Hussain, S.A., Badola, R., and Dahdouh-Guebas, F., 2008. Ethnobiology, socio-economic and management of mangrove forests: a review. Aquatic Botany, 89(2), 220-236. 